\title{
Flow Structure Investigation Heat Transfer Enhancement on Inner Tubular Pipe with Winglet Vortex Generator
}

\author{
Stefan Mardikus ${ }^{1, \text { a) }}$, Malfin ${ }^{2,}$ I Made Wicaksana Ekaputra ${ }^{3}$ \\ ${ }^{1,2,3}$ Sanata Dharma University, Yogyakarta \\ ${ }^{a)}$ stefan@usd.ac.id
}

\begin{abstract}
Vortices phenomenon becomes one of solutions to enhance heat transfer performance in shell-and-tube type of heat exchanger. Vortex generator is a device that can generate moving vortices of fluid to get good mixing fluid in heat transfer. The aim of this study is to find the effect of rectangular and delta winglet vortex generator if they are applied in inner tubular pipe heat exchanger, especially for shell-and-tube heat exchanger. Two types of winglet vortex generator were mounted in inner circular pipe then examined in turbulent flow with 6000-10000 Reynold numbers. The result of simulation showed that the use of rectangular and delta winglet can improve heat transfer performance.
\end{abstract}

\section{INTRODUCTION}

In Recent years, Heat Exchanger is a device to transfer heat in fluid thermal condition. Heat exchanger is more important in industrial such as power plant, air conditioning system, food technology and energy storage system. Shell-and-tube is one of types heat exchanger. Development of innovation to augment heat transfer performance on shell and tube heat exchanger is still being invented. Vortices phenomenon appears in flow structure to generate the heat transfer coefficient with the use of vortex generator. Vortex generator is passive technology to increase fluid mixing in heat transfer through different region between high pressure to low pressure when flow of the fluid hits the vortex generator. Through this indication, the tendency of heat transfer coefficient as one of the performance parameters is increasing. However, the use of vortex generator can produce high pressure drop while Nusselt number goes up[1]. Better efficiency, compact design, good heat transfer, and low pressure drop are main requirement of heat exchanger. Several types of vortex generator like rectangular, delta, trapezoidal can use longitudinal vortices. To enhance heat transfer performance in shell-and-tube type, vortex generator is mounted in circular pipe to result increasing of mixing thermal. Based on characteristic of distinguish, vortex generator contains of two motion in flow structure such as vortices of transverse and streamwise. In transverse, flow recirculation is behind of vortex generator then motion of rotation to direction flow as perpendicular while in streamwise, move swirling to flow direction [2]. Study about characteristic of vortex generator in open channel always develop like as Zhiming Xu studies about effect of vortex generator in rectangular channel to performance of heat transfer and flow resistance [3]. Through design and arrangement like as radius, spacing, vortex generator can augment thermal hydraulic performance. as above mentioned, problem studies about vortex generator in open channel were always investigated to optimal performance in any conditions. The present study will be simulated that compare of vortex generator types such as rectangular and delta winglet vortex generators in inner tubular pipe using R-12 as working fluid. Through this simulation, effect of vortex generator can be founded to get the best performance from use of vortex generator types. 


\section{MODEL AND COMPUTATIONAL DESCRIPTIONS}

The circular tube with delta and rectangular winglet vortex generators is descripted in Fig. 1. The arrangement of winglet vortex generator consisting of 6 rows and each row have 4 winglet pairs of vortex generator with distance between one pair with another pairs of winglet vortex generators of $100 \mathrm{~mm}$. The diameter of inner circular tube is $47.8 \mathrm{~mm}$ with $700 \mathrm{~mm}$ as the length of circular pipe. For rectangular and delta winglet vortex generators, isometric view and detail sizing are performed within Fig. 2. The boundary condition for this simulation was illustrated that range Reynold number started from 6000 to 10000 with 1000 as interval. The turbulence model was applied in this simulation using k-omega and R-12 was used as fluid [4].



[a]

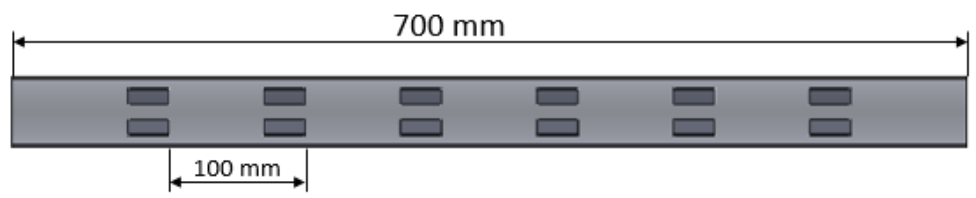

[b]

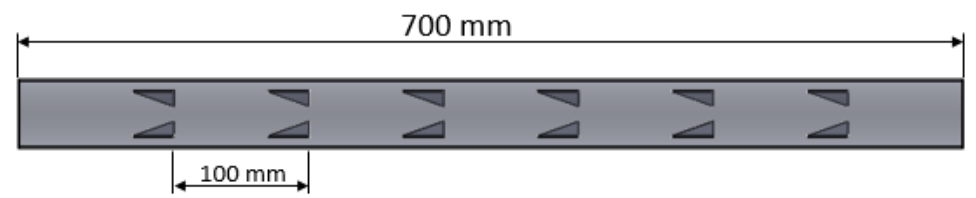

[c]

Figure 1. a. diameter description in right view of circular tube, $b$. front view rectangular and delta winglet vortex generators in circular tube of pipe length descriptions. 



Figure 2. Isometric view of rectangular and delta winglet vortex generator

\section{RESULT AND DISCUSSION}



Figure 3. Correlation of Reynolds number and Nusselt number for different vortex generators

Fig. 3 indicated that Nusselt number of rectangular and delta winglet vortex generators significantly increase higher than without vortex generator. This case means that use of vortex generator could improve heat transfer performance on circular pipe because it can make more good of thermal mixing in circular pipe and modify boundary layer. Moreover, longitudinal vortices that generated by rectangular and delta winglet vortex generator can increase fluid mixing intensity, thus; the heat transfer will be occurred on low thermal fluid [4][5] . 


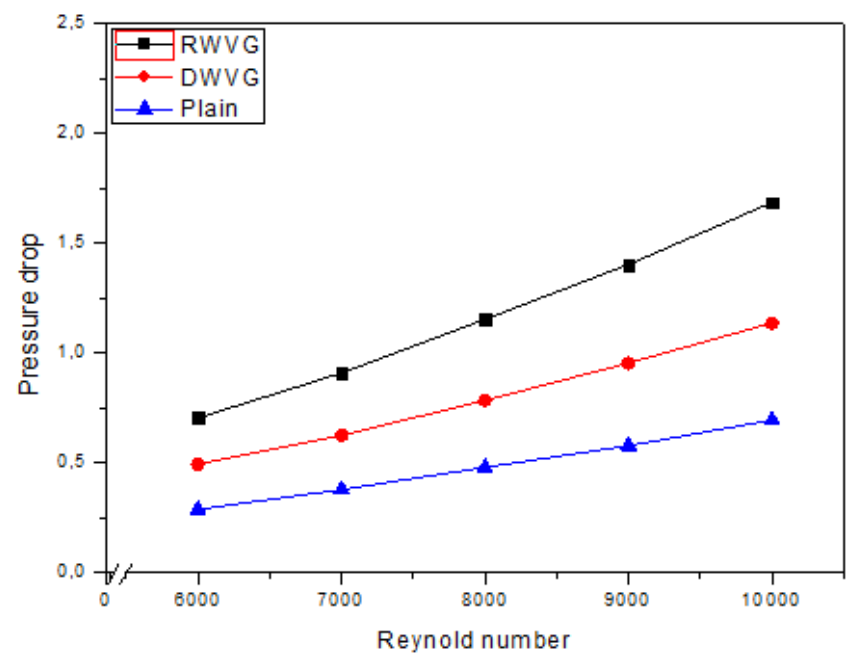

Figure 4. Correlation of Reynolds number and pressure drop for different vortex generators

In Fig 4, pressure drop purposes to know the disadvantages of fluid flow that pass into cylinder pipe as consequence addition of vortex generator. The use of rectangular and delta winglet vortex generators generated high flow resistance on fluid flow that pass vortex generator and wake phenomenon in behind of vortex area so the pressure drop was increase. The highest of pressure drop occurred on rectangular winglet vortex generator than delta winglet vortex generator and without vortex generator[6][5].



Figure 5. Schematic of 3 cross sectional area $(\mathrm{z} / \mathrm{D}=5.96 ; \mathrm{z} / \mathrm{D}=6.27 ; \mathrm{z} / \mathrm{D}=6.59)$ 


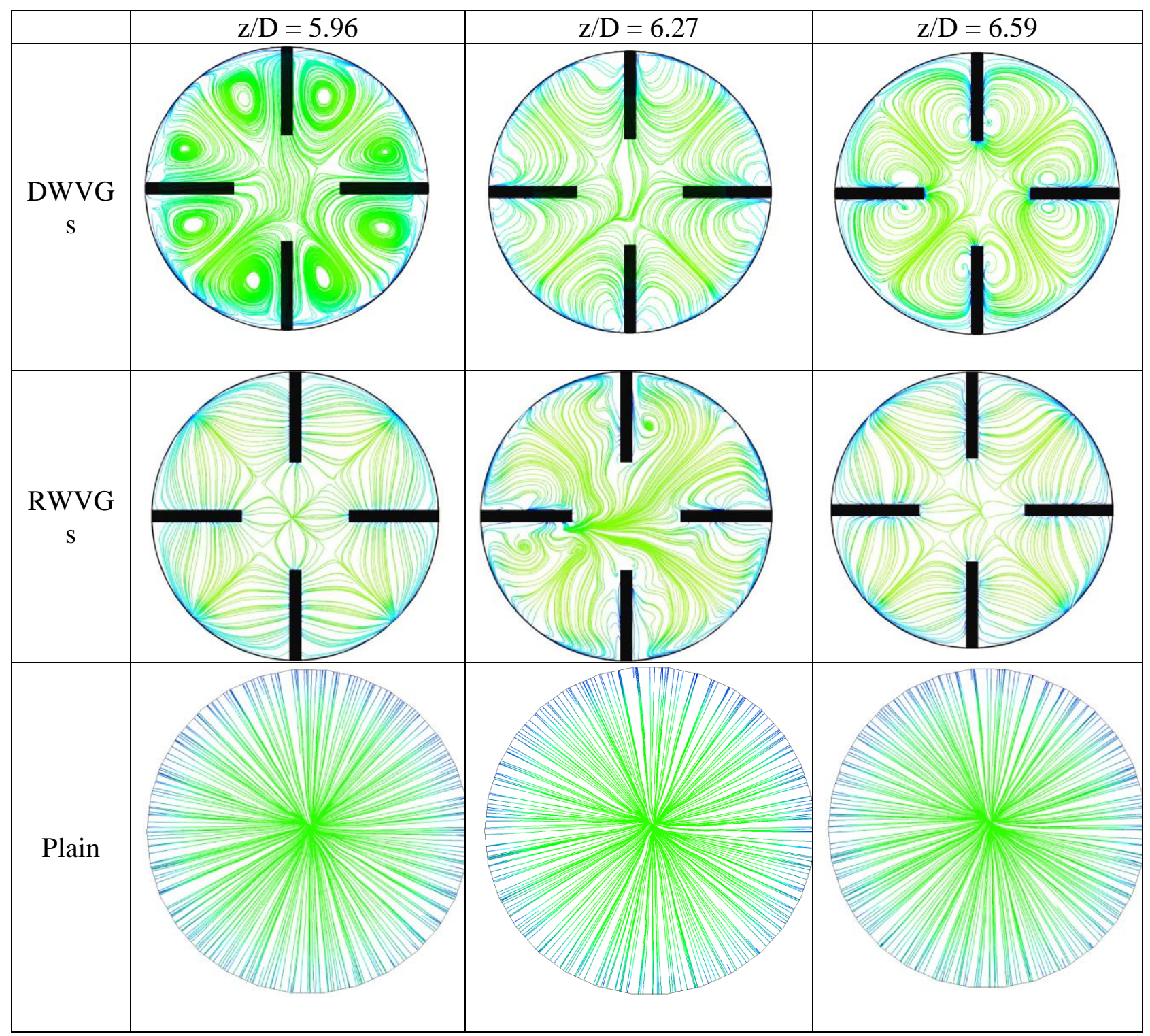

Figure 5. Streamline for $\mathrm{Re}=6000$ at 3 cross section

Wake on vortex generator which is area of low momentum flow will interact with flow core as high momentum flow that can become high pressure as the phenomenon of counter rotating vortex formation which have effect of temperature gradient increasing and heat transfer coefficient [7]. In Fig 5, wake phenomenon could be seen on DWVGs and RWVGs. For DWVGs and RWVGs, vortices appeared on the pipe wall, thus; it produced heat transfer enhancement because highest turbulent kinetic energy and thermal mixing improvement in wake regions [8][9].

\section{CONCLUSION}

Result of investigation about simulation of heat transfer performance in circular pipe with two types vortex generator, rectangular and delta winglet types was performed using computational fluid dynamic. Nusselt number and pressure drop parameters were used to represent heat transfer performance. Moreover, contour of temperature 
distribution and streamline velocity were used to identify the characteristic of flow structure in heat transfer enhancement. The primary conclusion was summarized as follow as;

1. The use of rectangular and delta winglet can improve performance of heat transfer by Nusselt number parameter. Moreover, this identification showed that use of rectangular winglet vortex generator had the highest Nusselt number more than delta winglet vortex generator and without vortex generator in circular pipe.

2. Wake region appeared when use of delta and rectangular vortex generator in cylinder pipe because highest turbulent kinetic energy and thermal mixing improvement that can increase heat transfer coefficient.

\section{REFERENCES}

[1] S. Chamoli, R. Lu, J. Xie, and P. Yu, Appl. Therm. Eng., vol. 135, pp. 304-324, 2018.

[2] C. Habchi et al., Appl. Therm. Eng., vol. 38, pp. 14-25, 2012.

[3] Z. Xu, Z. Han, J. Wang, and Z. Liu, Int. J. Heat Mass Transf., vol. 116, pp. 61-72, 2018.

[4] Y. Lei, F. Zheng, C. Song, and Y. Lyu, Int. J. Heat Mass Transf., vol. 111, pp. 299-311, 2017.

[5] Y. Xu, M. D. Islam, and N. Kharoua, Int. J. Therm. Sci., vol. 112, pp. 304-317, 2017.

[6] Z. Han, Z. Xu, and J. Wang, Int. J. Heat Mass Transf., vol. 126, pp. 993-1001, 2018.

[7] C. Habchi and J. L. Harion, Int. J. Heat Mass Transf., vol. 74, pp. 13-24, 2014.

[8] G. Liang, M. D. Islam, N. Kharoua, and R. Simmons, Int. J. Therm. Sci., vol. 134, no. June, pp. 54-65, 2018.

[9] G. Zhou and Z. Feng, Int. J. Therm. Sci., vol. 78, pp. 26-35, 2014. 